\title{
Performance analysis of brushless DC motor with optimum magnetic energy for bicycle application
}

\author{
Muhamad Ariff Khalid ${ }^{1}$, Raja Nor Firdaus Kashfi Raja Othman², Nor Aishah Md Zuki ${ }^{3}$, Fairul Azhar \\ Abdul Shukor ${ }^{4}$, Md Nazri Othman ${ }^{5}$, Chockalingam Aravind Vaithilingam ${ }^{6}$ \\ 1,2.3,4,5Fakulti Kejuruteraan Elektrik, Universiti Teknikal Malaysia Melaka, Melaka, Malaysia \\ 1,2.3,4,5Electrical Machine Design Research Laboratory, Centre of Robotics \& Industrial Automation (CeRIA), Universiti \\ Teknikal Malaysia Melaka, Melaka, Malaysia \\ ${ }^{6}$ School of Engineering, Taylor's University Malaysia, Subang Jaya, Malaysia
}

\begin{tabular}{|c|c|}
\hline Article Info & ABSTRACT \\
\hline & \multirow{8}{*}{$\begin{array}{l}\text { Brushless DC (BLDC) motor is widely used for various applications such as } \\
\text { transportation. BLDC motor has many advantages compared to brush motor } \\
\text { such as more compact, high robustness and simplest construction. The } \\
\text { maintenance of this motor also low compared to brush motor due to absent of } \\
\text { the brush inside the motor. For electric bicycle application, the conventional } \\
\text { motor has low electromagnetic torque because not properly designed. It faces } \\
\text { low torque density as the motor in full load condition especially during climb } \\
\text { uphill. In this research, an optimum magnetic energy is being determine by } \\
\text { proper selection of permanent magnet size. In addition, this research also } \\
\text { increases the input current in dynamic condition into the designed BLDC } \\
\text { motor. Finite element method (FEM) is used to analyze other performance } \\
\text { characteristic of improved motor such as back electromotive force (EMF), } \\
\text { electromagnetic torque, flux linkage, and stator flux density. Parameter for } \\
\text { improve the current motor are selected and varied based on the required } \\
\text { specification. In conclusion, the research proposed the new motor specification } \\
\text { that has highest electromagnetic torque of brushless DC motor. Finally, this } \\
\text { research provides guidelines, suggestions and proposes a better improved } \\
\text { structure in optimize the magnetic energy in BLDC motor. }\end{array}$} \\
\hline Received Jun 6, 2021 & \\
\hline Revised Aug 28, 2021 & \\
\hline Accepted Sep 15, 2021 & \\
\hline Keywords: & \\
\hline Bicycle application & \\
\hline BLDC & \\
\hline Magnetic energy & \\
\hline
\end{tabular}

This is an open access article under the CC BY-SA license.

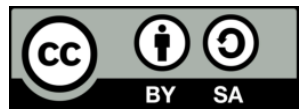

\section{Corresponding Author:}

Raja Nor Firdaus Kashfi Raja Othman

Fakulti Kejuruteraan Elektrik

Universiti Teknikal Malaysia Melaka

76100 Durian Tunggal, Melaka

Email: norfirdaus@utem.edu.my

\section{INTRODUCTION}

The brushless motor are generally preferred in industries compared to induction motor [1]-[5]. The Brushless motors are divided into two type that namely permanent magnet synchronous motor (PMSM) and the permanent magnet brushless DC (PMBLDC) motor [6]-[8]. They have different characteristics, especially in the back EMF output wave. A sinusoidal wave is the characteristic output of PMSM motor [7], [9]-[11]. While the trapezoidal waveform of the PMBLDC motors is for the back EMF output [12]. Typically, the construction of a brushless motor system is similar to a permanent magnet synchronous motor (PMSM) [13][15]. PMBLDC motor uses permanent field excitation magnets on the rotor and electronically switched stator winding [7], [16]-[18]. Compared to induction motors, the rare earth magnets help to make these motors efficient and compact [19]-[22]. Although less efficient than three-phase PM BLDC motors, single-phase PM 
BLDC motors are cost-effective and easy to mass-produce [23]. These are used in applications ranging from a fraction of watts to less than hundred watts which need output power [24].

Most of the current electric bicycle nowadays difficult to handle. The unsuitable size of motor affects the wheel balancing. It is because the size and volume of the motor used by manufacture is not compact when compared to weight of the bicycle [1], [24]-[26]. The user has difficulties to control their vehicle during turning the road. In other issue, low torque density motor can cause more current to accelerate. This situation automatically can make the winding of the motor become hot and also reduce the winding resistance [1], [14], [25]. Some of electric bicycle was unable to carry heavy load. The electric bicycle requires more electromagnetic torque to carry heavy load. When the electromagnetic torque produce by the motor is not enough, the electric bicycle become slower during climbing. This scenario also can cause the winding inside the motor become overheated and caused the motor damaged [1]. This factor can reduce the lifespan of the electric bicycle [1]. The electromagnetic torque of the motor affect by the number of poles. 16 poles can achieve at least $79 \%$ of efficiency [4].

In this research, the size of the motor has been improved to prevent the motor become heavier at the same time to ensure that factor not affect the handling of the electric bicycle. To improve the performance of motor, the size of permanent magnet has been analyzed and maximized to optimize the magnetic energy. With optimized magnetic energy, the electromagnetic torque characteristic and back EMF characteristic also will be optimized. This research also analyzed the number of coils turns to maximize area around the stator teeth. With the larger diameter of coil used, it also can support higher input current into the motor. In addition, the motor can be more rugged than conventional motor. This way also can improve the total lifespan of the motor and electric bicycle.

\section{RESEARCH METHOD}

\subsection{Basic structure of BLDC motor in this research}

In this research, the target specification of the BLDC motor is $100 \mathrm{~W}$. The basic structure of the model shown in Figure 1. The component of the motor consists of permanent magnet, rotor, stator, and coil. The stator and rotor are made from non-oriented silicon steel (M250)-35 A and neodymium boron iron (NdFeB 42) for permanent magnet. The coil is made from copper with $0.75 \mathrm{~mm}$ diameter. Therefore, it required suitable input current to produce optimum value of electromagnetic torque. The design specification is shown in Table 1.
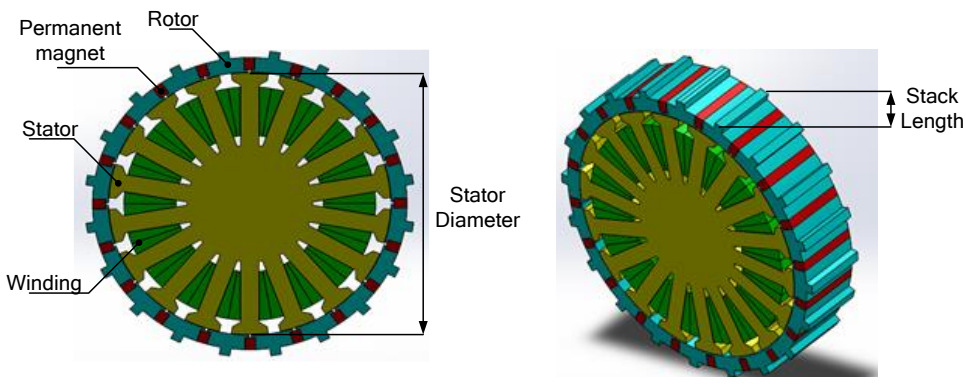

Figure 1. Basic structure of BLDC motor in this research

Table 1. Design specification

\begin{tabular}{lll}
\hline Motor Parameter & {$[$ Unit] } & Specification \\
\hline Rated power & {$[\mathrm{W}]$} & 100 \\
Phase number & 3 \\
Pole number & 20 \\
Stator slot & 18 \\
Permanent Magnet type & & Neodymium Iron Boron (NdFeB) \\
Air gap & {$[\mathrm{mm}]$} & 0.2 \\
Stack length & {$[\mathrm{mm}]$} & 28 \\
\hline
\end{tabular}

\subsection{Analysis parameter of research BLDC motor}

Table 1 show the design specification that will be fixed for all model of BLDC in the analysis while Table 2 is the varied parameter for each model in this research. Based on Table 1, the pole number and stator slot number are 20 and 18, respectively. The air gap of the BLDC motor is $0.2 \mathrm{~mm}$. The stator stack length is set 28 $\mathrm{mm}$ and its equal to permanent magnet thickness. Based on Table 2, the size of permanent magnet and the number 
of coils turns has been varied. In FEM analysis, the researcher has set multiple input current and various speed for each BLDC model. The result that gained from the FEM has been analyzed and compared from all models.

The motor will be modeled in various size of permanent magnet while the size of stator remains constant. Table 2 shown the various size of permanent magnet, which are $2 \times 4,2 \times 5,4 \times 4,4 \times 5$ in mm and other varied parameters. These various models will be developed using computer aided design (CAD) software.

Table 2. Varied parameter for BLDC motor

\begin{tabular}{lll}
\hline \multicolumn{1}{c}{ Parameters } & [Unit] & \multicolumn{1}{c}{ Values } \\
\hline Size of permanent magnet & {$[\mathrm{mm}]$} & $2 \times 4,2 \times 5,4 \times 4,4 \times 5$ \\
Winding turns & {$[$ turns $]$} & 25 and 35 \\
Coil size & {$[\mathrm{mm}]$} & 0.5 and 0.7 \\
Input current & {$[\mathrm{A}]$} & $0,1,2,4,6,8,10$ \\
Speed & {$[\mathrm{rpm}]$} & $100,200,300,400,500$ \\
\hline
\end{tabular}

After the assembly process in CAD is successful, the 3D model will be exported to ANSYS maxwell for FEM modelling. Basically, it requires time to develop the model depending upon the software requirement. Then, development of mesh will take place. The more detail of mesh, the more the accuracy of the result will be obtained. After mesh development is complete, the element calculation of the structure model will be declared. Next, material and other configuration such as simulation time, motion setup, and boundaries will be selected. For BLDC motor in this research, it has various size of permanent magnet. While maintaining the outer diameter of the motor and stator, the dimension of the rotor also should be varied to keep the size of permanent magnet fit into the motor.

In FEM, the electromagnetic properties of the motor will be analyzed to determine the characteristic of back EMF, electromagnetic torque, flux density, and flux linkage. The result produced by the FEM are more accurate compared to analytical because it calculates non-linear characteristic of electromagnet. The losses such as core and eddy effect loss are taking account by the FEM. After the first model has been analyzed using FEM, the same model will be changed with other size of permanent magnet, number of coils turns, input current, and speed as shown in Table 2. The number of coils is set to two types consist of 25 turns and 35 turns. For the model with 25 turns, the size of coil is $0.5 \mathrm{~mm}$ while for 35 turns is $0.7 \mathrm{~mm}$. Input current also will be set with various type consist of direct current (DC) for static analysis and alternating current (AC) for dynamic analysis. For the static analysis, the model will be input from zero input current until 8A while the dynamic analysis will be input from $1 \mathrm{~A}$ until $10 \mathrm{~A}$. Finally, the speed of the motor also will be varied from $100 \mathrm{rpm}$ to $500 \mathrm{rpm}$. All these varied parameters will be simulated in FEM environment. If the FEM result are found unsatisfactory, some parameter will be modified. The process is repeated until the result is acceptable.

The performance criteria that will be used for selection determination are back EMF, maximum electromagnetic torque, and stator flux density with optimum magnetic energy. All the analysis result of various model that been carried out from FEM will be compared to choose the most suitable model that has optimum magnetic energy based on the design specification as shown in Table 1. The overall research flowchart has been shown in Figure 2.

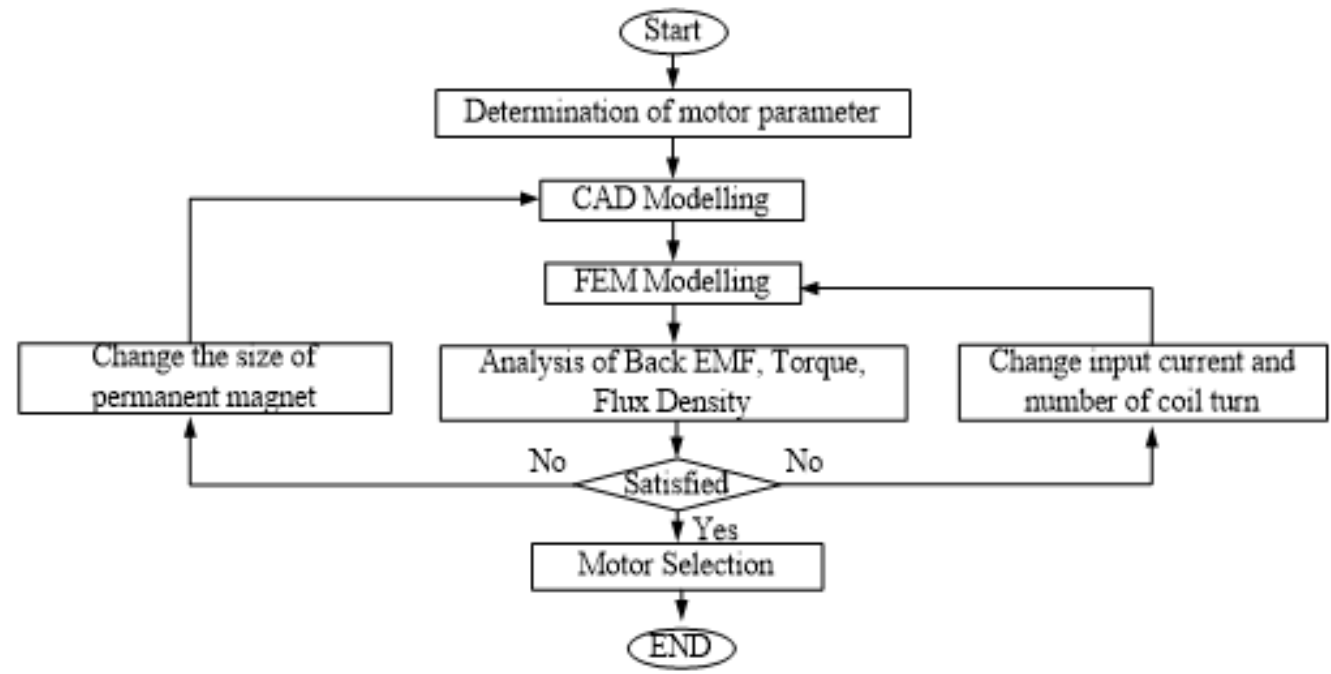

Figure 2. Overall research flowchart 


\section{RESULT AND DISCUSSION}

In this analysis, the design of the BLDC motor has been set to various type of speed from 100 to 500 rpm. To observe the effect of flux linkage, the model has been designed with various size of permanent magnet. The size of permanent magnet is $2 \times 4,2 \times 5,4 \times 4$, and $4 \times 5$ in $\mathrm{mm}$. The number of coils turn also has been set with different numbers which are 25 turns and 35 turns for all models.

\subsection{Simulation result}

In this simulation, the effect of flux linkage for all the models has been observed with zero input current $(0 \mathrm{~A})$ condition. Figure 3 (a) shows the flux linkage of the motor for the permanent magnet size 4x5 $\mathrm{mm}$. It shows the maximum flux linkage is $0.02 \mathrm{~Wb}$ and in three phase sinusoidal waveform. From Figure 3 (a), the value of maximum flux linkage is recorded and presented in Figure 3 (b). Based on this figure, the value of flux linkage affected by two variables which are permanent magnet size and the number of coils. The maximum value for flux linkage is $0.02 \mathrm{~Wb}$ for $4 \times 5 \mathrm{~mm}$ of permanent magnet with 35 number of coils turns per slot. But the maximum value of flux linkage for 25 coil turns is $0.015 \mathrm{~Wb}$ for $4 \times 5 \mathrm{~mm}$ permanent magnet. The lowest value of flux linkage for 35 number of coil turns is $0.009 \mathrm{~Wb}$ for $2 \times 5 \mathrm{~mm}$ of permanent magnet. While the lowest flux linkage for 25 coil turns is $0.005 \mathrm{~Wb}$ for $2 \times 5 \mathrm{~mm}$ permanent magnet. It can be concluded that the flux linkage is directly proportional to size of permanent magnet. It is because bigger size of the permanent magnet has higher magnetic energy. Then, it will affect the maximum value of the flux linkage of the motor.

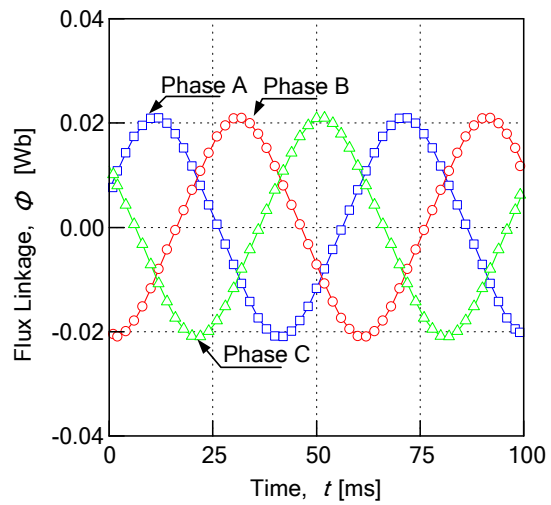

(a)

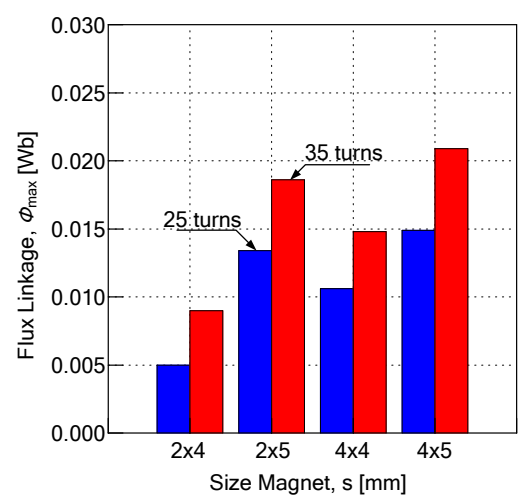

(b)

Figure 3. Analysis of flux linkage, (a) flux linkage for $4 \times 5 \mathrm{~mm}$ model with 35 coils turns, (b) maximum of flux linkage

In this analysis, the back EMF from all models has been observed with zero input current $(0 \mathrm{~A})$. Figure 4 shows the back EMF of the motor for permanent magnet size of $2 \times 5 \mathrm{~mm}$ with 35 coils turns at 200 rpm. It shows the maximum back EMF achieved at $4 \mathrm{~V}$ in balanced three phase sinusoidal waveform. From Figure 4, the maximum value of back EMF based on various size of permanent magnet, number of coils turns, and speed of motor is recorded by Figure 5.

Figure 5 shows the maximum back EMF in rms form vs speed for all sizes of permanent magnet. Each of the model has been analyzed with different speed starting from $100 \mathrm{rpm}$ to $500 \mathrm{rpm}$. The back EMF has been compared with different size of permanent magnet consist of $2 \times 4 \mathrm{~mm}, 2 \times 5 \mathrm{~mm}, 4 \times 4 \mathrm{~mm}$, and $4 \times 5$ $\mathrm{mm}$. It also has been compared with different number of coils consist of 25 and 35 turns.

Figure 5 (a) shows the maximum back EMF for $2 \times 4 \mathrm{~mm}$ permanent magnet sizes. For $2 \times 4 \mathrm{~mm}$ permanent magnet size, the maximum back EMF for 25 and 35 number of coil turns is $22 \mathrm{mV}$ and $30 \mathrm{mV}$, respectively. The back EMF for Figure 5 (a) is directly proportional to speed. Based on Figure 5 (b), the maximum back EMF of $2 \times 5 \mathrm{~mm}$ permanent magnet size for 25 and 35 number of coil turns is $7 \mathrm{~V}$ and $10 \mathrm{~V}$, respectively. The back EMF produced is increase when the speed of the motor increases. The Figure 5 (c) shows the maximum back EMF of $4 \times 4 \mathrm{~mm}$ permanent magnet size is increased up to $5 \mathrm{~V}$ and $8 \mathrm{~V}$ for 25 and 35 number of coils turns, respectively. The back EMF for Figure 5 (c) shows similar patten with Figures 5 (a) and (b). Based on Figure 5 (d), it shows the maximum back EMF of 4x5 mm permanent magnet size for 25 and 35 number of coil turns is increased up to $8 \mathrm{~V}$ and $11 \mathrm{~V}$, respectively. 
In conclusion, the permanent magnet volume will affect by the back EMF. Higher the volume of the permanent magnet, higher the magnetic energy produced by the motor. The back EMF was the result of the permanent magnet flux crossing the air gap in radial direction and cutting the coil of the stator at a rate of proportional to the rotor speed. The higher the number of coils turns, the higher the back EMF produced by the motor. Here, back EMF is directly proportional to number of coil and speed.

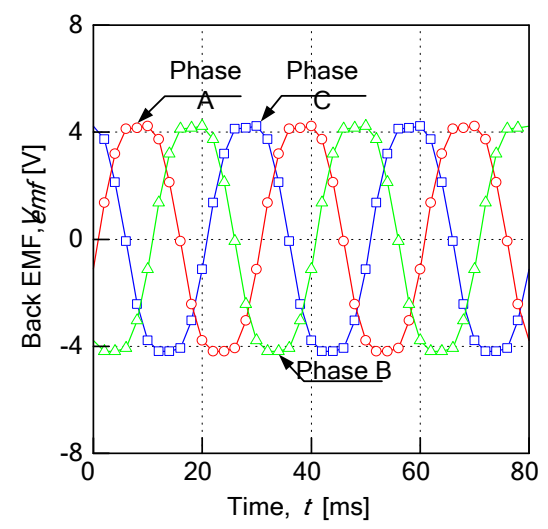

Figure 4. Back EMF in simulation analysis for $2 \times 5 \mathrm{~mm}$ model

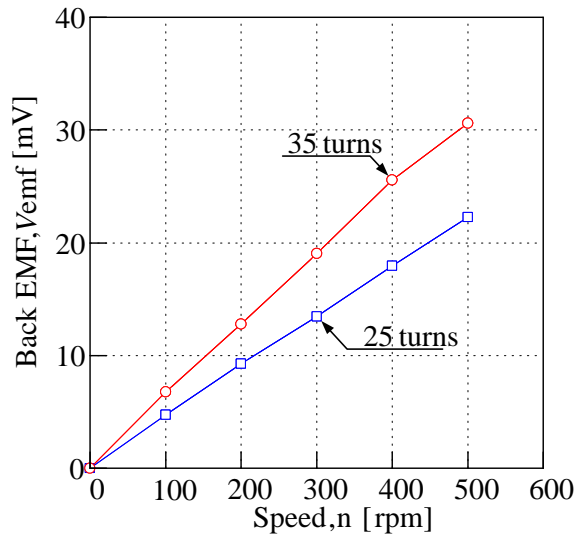

(a)

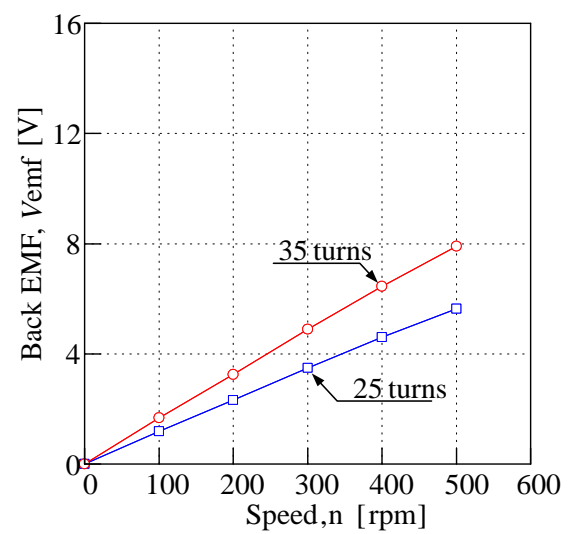

(c)

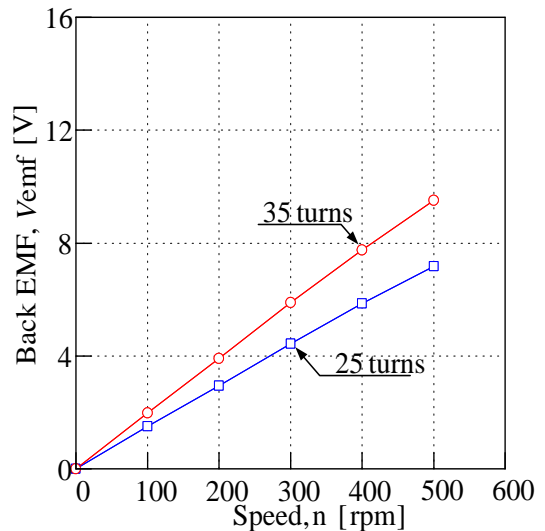

(b)

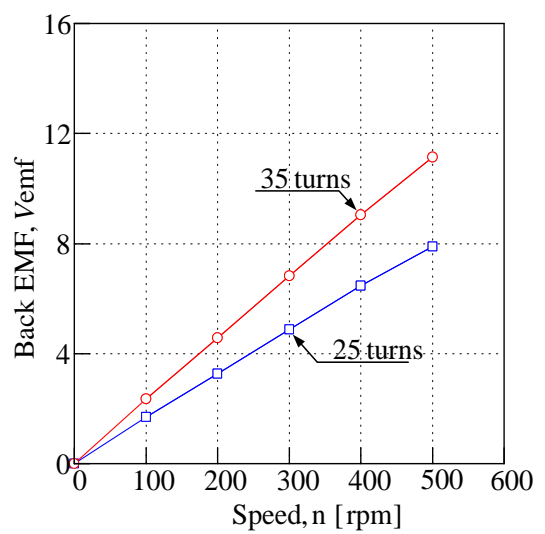

(d)

Figure 5. Back EMF for different permanent magnet size, (a) 2x4 mm, (b) $2 \times 5 \mathrm{~mm}$, (c) $4 \times 4 \mathrm{~mm}$, (d) $4 \times 5 \mathrm{~mm}$ 
Figure 6 shows the result of flux density distribution in simulation for $4 \times 5 \mathrm{~mm}$ size of permanent magnet with 35 turns coil and $8 \mathrm{~A}$ of input current. The highest value of flux density point reaches up to $1.3 \mathrm{~T}$ which does not reach the saturation. The maximum flux density can be traced at the middle of the stator pole. The flux density also has been traced existing at rotor part. The maximum value of flux density occurs at rotor in average 1.3 T. However, there are certain area that achieved $2.3 \mathrm{~T}$ but it can be ignored. It is because that area is the gap that used as flux barrier of each permanent magnet pole. This flux barrier will reduce the flux leakage that going back to the permanent magnet itself. It can be concluded that the smallest area of the part, the higher flux density will be occurred.

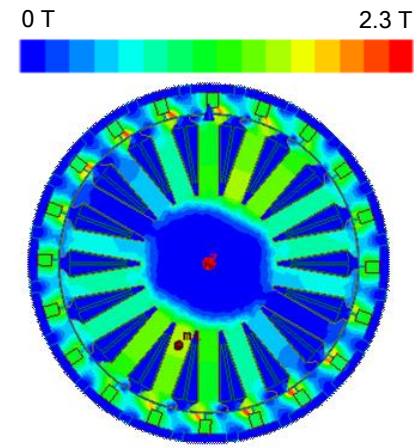

Figure 6. Magnetic flux density distribution in simulation analysis for 4x5 mm model

The highest value of stator flux density gain by the all model has been analyzed and recorded in Figure 7 . Each of the model has been analyzed with various input current starting from zero input current $(0 \mathrm{~A})$ to $8 \mathrm{~A}$ input current. The value of flux density has been compared with different size of permanent magnet consist of $2 \times 4,2 \times 5$, $4 \times 4$, and $4 \times 5$ in $\mathrm{mm}$. It also has been compared with different number of coils consist of 25 and 35 turns.

Figure 7 shows the stator flux density for different size of permanent magnet. For Figure 7 (a), the $2 \times 4 \mathrm{~mm}$ permanent magnet size, the stator flux density can achieve to $1.2 \mathrm{~T}$ and $1.4 \mathrm{~T}$ for number of coil turns is 25 and 35 , respectively. The stator flux density of Figure 7 (a) is increase directly proportional to input current of the motor. Based on Figure 7 (b), it shows $2 \times 5$ mm permanent magnet size with for 25 and 35 number of coils turns has maximum stator flux density of $1.4 \mathrm{~T}$ and $1.5 \mathrm{~T}$, respectively. The stator flux density start increases when the input current is $2 \mathrm{~A}$. The stator flux density remained at maximum point of $1.5 \mathrm{~T}$ for $4 \times 4 \mathrm{~mm}$ and $4 \times 5 \mathrm{~mm}$ of permanent magnet with 35 number of coils turns. In directly, the stator flux density for $4 \times 5 \mathrm{~mm}$ permanent magnet with number of coils turns of 25 turns is $1.3 \mathrm{~T}$. For Figure 7 (c), the stator flux density starts to increase from $0.50 \mathrm{~T}$ when input current is 2 A. Meanwhile, for Figure 7 (d), the stator flux density starts to increase at 4 A of input current.

In conclusion, the permanent magnet volume will affect the stator flux density. Moreover, higher volume of the permanent magnet, greater the magnetic energy produced by the motor. The greater the number of coils turns, the higher the gradient of the stator flux density until it saturated. It can be concluded that stator flux density is increase when the number of coil increases. The stator flux density also increases until it saturated when the input current increased.

In this analysis, Figure 8 shows the electromagnetic torque with $4 \mathrm{~A}$ of input current in simulation analysis for $2 \times 5 \mathrm{~mm}$ of permanent magnet size. This analysis has been set with constant $200 \mathrm{rpm}$ of speed for all motor. The highest point of electromagnetic torque is around $3 \mathrm{Nm}$ and $5 \mathrm{Nm}$ for $2 \times 5 \mathrm{~mm}$ permanent magnet size with 25 and 35 coils turns, respectively. Each electromagnetic torque has same pattern with different number of coils turns.

The average electromagnetic torque recorded from Figure 8 and another model is presented at Figure 9. Each of the model has been analyzed with different value of input current starting from 0 A until 10 A. Each of the average of electromagnetic torque has been compared with different size of permanent magnet consist of $2 \times 4,2 \times 5,4 \times 4$, and $4 \times 5$ in $\mathrm{mm}$. In this analysis, the electromagnetic torque also has been compared with various number of coils turns consist of 25 and 35 turns.

For Figure 9 (a), it shows the highest average of electromagnetic torque for 25 and 35 number of coils turns with $2 \times 4 \mathrm{~mm}$ of permanent magnet size is $0.24 \mathrm{Nm}$ and $0.38 \mathrm{Nm}$, respectively. The electromagnetic torque for Figure 9 (a) is increases directly proportional to input current at the motor. For $2 \times 5 \mathrm{~mm}$ of permanent magnet size in Figure 9 (b), it increased up to $3.0 \mathrm{Nm}$ and $4.0 \mathrm{Nm}$ for 25 and 35 coil turns, respectively. Based on Figure 9 (b), the electromagnetic torque of the motor increase as the input 
current of the motor increases. Figure 9 (c) shows the $4 \times 4 \mathrm{~mm}$ of permanent magnet size with average of electromagnetic torque for 25 and 35 number of coil turns is $2.5 \mathrm{Nm}$ and $3.0 \mathrm{Nm}$, respectively. The electromagnetic torque produce by the motor is higher when the input current of the motor is higher. Based on Figure 9 (d), it shows the highest average of electromagnetic torque of $4 \times 5 \mathrm{~mm}$ permanent magnet size are $3.3 \mathrm{Nm}$ and $4.5 \mathrm{Nm}$ for 25 and 35 number of coils turns, respectively. In this Figure 9 (d), the electromagnetic torque is higher when the input current is greater. In conclusion, the permanent magnet volume also will affect the electromagnetic torque produced by the motor. More surpassing the volume of the permanent magnet, greater the magnetic energy produced by the motor. The higher the number of coils turns, the higher the electromagnetic torque of the motor.

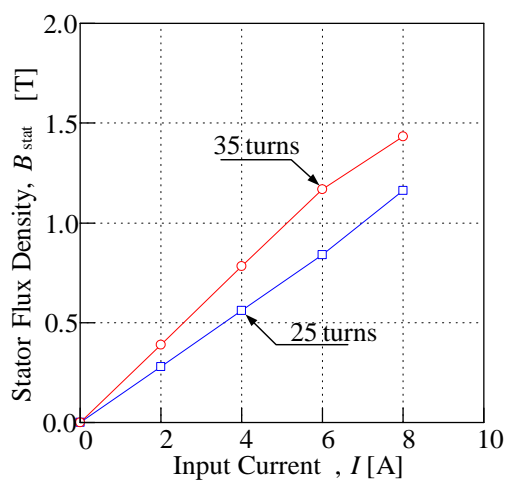

(a)

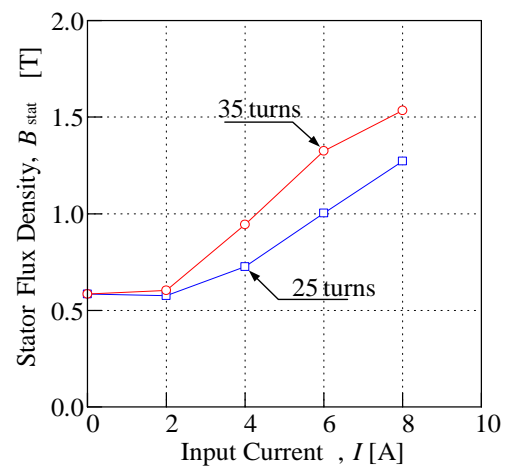

(c)

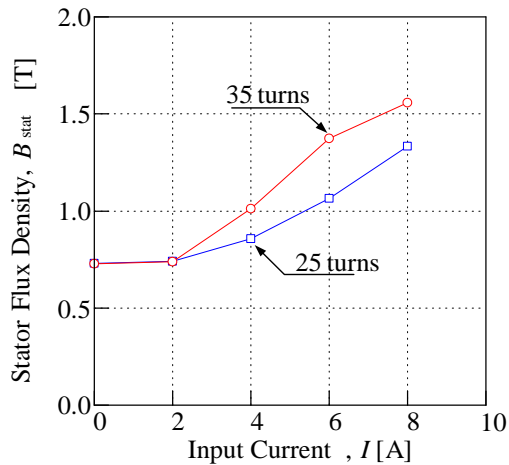

(b)

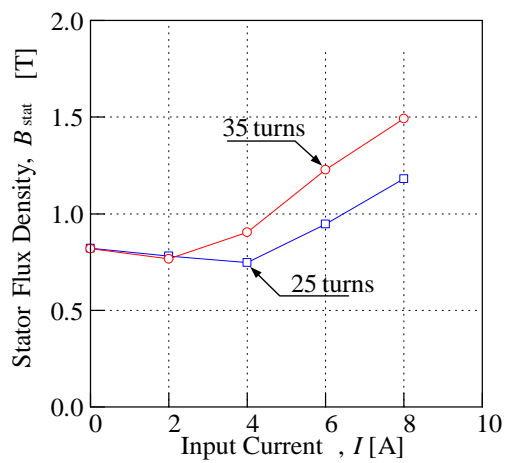

(b)

Figure 7. Flux density for different size of permanent magnet, (a) $2 \times 4 \mathrm{~mm}$, b) 2x5 mm c) 4x4 mm, d) $4 \times 5 \mathrm{~mm}$

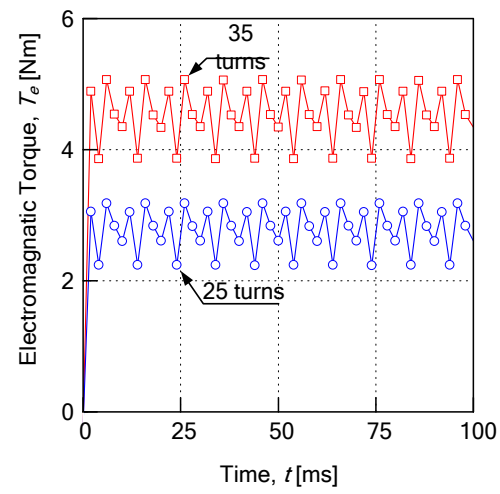

Figure 8. Electromagnetic torque with $4 \mathrm{~A}$ of input current for $2 \times 5 \mathrm{~mm}$ model 


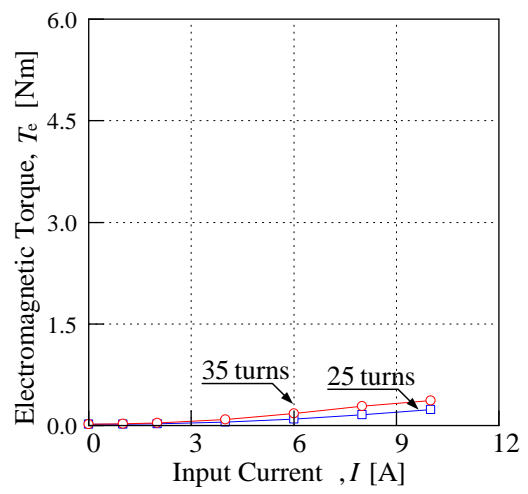

(a)

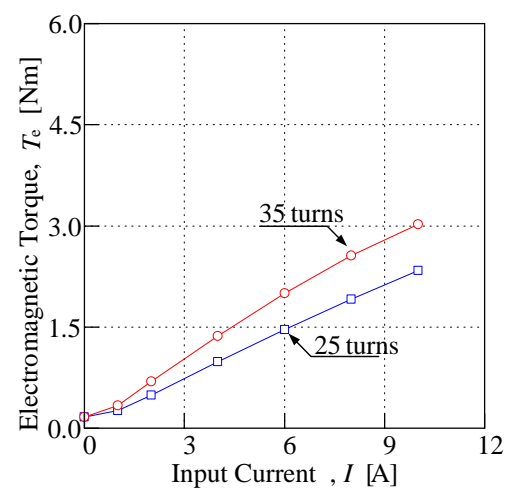

(c)

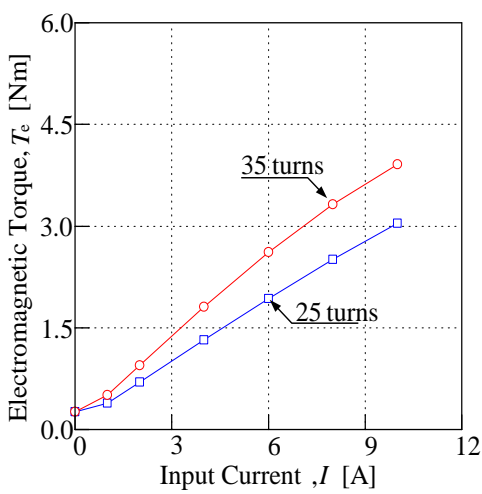

(b)

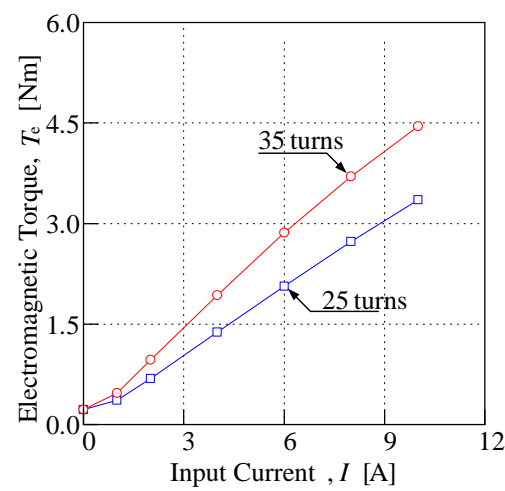

(d)

Figure 9. Average electromagnetic torque for different size of permanent magnet, (a) $2 \times 4 \mathrm{~mm}$, (b) $2 \times 5 \mathrm{~mm}$, (c) $4 \times 4 \mathrm{~mm}$, (d) $4 \times 5 \mathrm{~mm}$

\subsection{Result selection}

Based on all performance analysis that been discussed previously, this section explained, and conclude the best criteria as the final model. Before the best model is chosen, the performance characteristic that being considered are flux linkage, back EMF, stator flux density, and electromagnetic torque. Depend on Table 3, the back EMF produced by $4 \times 5 \mathrm{~mm}$ of permanent magnet size with 35 coils turns is $11 \mathrm{~V}$. When compared to another selected model, the back EMF from this model is the highest. Back EMF from $2 \times 5 \mathrm{~mm}$ of permanent magnet size with 35 coil turns is lower than the first selected model which is $9 \mathrm{~V}$. Meanwhile, the lowest back EMF from all selected model is $8 \mathrm{~V}$ from $4 \times 5 \mathrm{~mm}$ of permanent magnet size with 25 coils turns.

Flux density for this section is taken from one value of input current before the model reach the saturation state. In this research, the saturation state of flux density for each model is around $1.5 \mathrm{~T}$. In this comparison, flux density from all selected models analyzed at $6 \mathrm{~A}$ of input current. This point is selected because each model has reached the highest value of flux density before it saturated. Based on Table 3, flux density from $2 \times 5 \mathrm{~mm}$ of permanent magnet size with 35 coils turns is $1.4 \mathrm{~T}$. This model followed by $1.3 \mathrm{~T}$ from $4 \times 5 \mathrm{~mm}$ of permanent magnet size with 35 coils turns. The lowest flux density is $1.0 \mathrm{~T}$ from $4 \times 5 \mathrm{~mm}$ of permanent magnet size with 25 coils turns. Therefore, flux density from $4 \times 5 \mathrm{~mm}$ of permanent magnet is most ideal compared with other two selected model. It is because the flux density from this model does not reach the saturation point compared to $2 \times 5 \mathrm{~mm}$ of permanent magnet size. Flux density from $4 \times 5 \mathrm{~mm}$ of permanent magnet size with 25 coils turns is too low compared to $4 \times 5 \mathrm{~mm}$ of permanent magnet size with 35 coils turns. Based on Table 3, the electromagnetic torque from $4 \times 5 \mathrm{~mm}$ of permanent magnet size with 35 coils turns is the highest. The highest electromagnetic torque achieved is $4.5 \mathrm{Nm}$. Model $2 \times 5 \mathrm{~mm}$ of permanent magnet size with 35 coils turns has $3.8 \mathrm{Nm}$ of electromagnetic torque while the lowest electromagnetic torque in selected model is $3.2 \mathrm{Nm}$ for $4 \times 5 \mathrm{~mm}$ of permanent magnet with 25 coils turns.

Based on Table 3, model with $4 \times 5 \mathrm{~mm}$ of permanent magnet with 35 coils turns is the best model compared to other. This model reaches the higher value of flux linkage with balance waveform $(0.020 \mathrm{~Wb})$. This model followed by the $2 \times 5 \mathrm{~mm}$ of permanent magnet size with 35 coils turns. The flux linkage from this model is $0.018 \mathrm{~Wb}$. The lowest flux linkage is $0.015 \mathrm{~Wb}$ from $4 \times 5 \mathrm{~mm}$ of permanent magnet with 25 coils turns. The best back EMF has produced from $4 \times 5 \mathrm{~mm}$ of permanent magnet size with 35 coils turns. 
Table 3. Selected model with performance characteristic

\begin{tabular}{|c|c|c|c|c|c|}
\hline Model & Coils Turns & [Wb] & $V_{\mathrm{emf}}$ & $B_{\text {stat }}$ & {$[\mathrm{Nm}]$} \\
\hline $4 \times 5$ & 35 & 0.020 & 11 & 1.3 & 4.5 \\
\hline $2 \times 5$ & 35 & 0.018 & 9 & 1.4 & 3.8 \\
\hline $4 \times 5$ & 25 & 0.015 & 8 & 1.0 & 3.2 \\
\hline
\end{tabular}

\section{CONCLUSION}

Based on the analysis, the performance of electromagnetic torque and back EMF of the motor can be improved by increasing the size of permanent magnet. This is because the higher volume of permanent magnet produced higher magnetic energy. Model 4x5 mm of permanent magnet has the optimum magnetic energy because it has higher flux linkage, back EMF and electromagnetic torque compared to another model. In addition, the higher number of coils turns apply to the motor also can improved the motor electromagnetic torque and back EMF characteristics. Besides that, the electromagnetic torque characteristic of the motor will be affected by the value of input current.

\section{ACKNOWLEDGEMENTS}

The authors would like to thank Ministry of Higher Education Malaysia, Universiti Teknikal Malaysia Melaka (UTeM) for providing the research grant of MTUN/2019/FKECERIA/MC0003.

\section{REFERENCES}

[1] D. Zhen, Y. Zhou Deng, and Y. Luo, "Rising of Electric Bicycle in China," Journal of Iron and Steel Research International, vol. 13, pp. 378-382, December 2006, doi: 10.1016/S1006-706X(08)60213-7.

[2] C. He, and T. Wu, "Permanent magnet brushless dc motor and mechanical structure design for the electric impact wrench system," Energies, vol. 11, no. 6, p. 1360, May 2018, doi: 10.3390/en11061360.

[3] B. V. R. Kumar and K. S. Kumar, "Design of a new Dual Rotor Radial Flux BLDC motor with Halbach array magnets for an electric vehicle," 2016 IEEE International Conference on Power Electronics, Drives and Energy Systems (PEDES), 2016, pp. 1-5, doi: 10.1109/PEDES.2016.7914552.

[4] J. S. Yoo, et al., "Analysis of Optimize Designing Small Size BLDC Motor Considering Air Gap Clearance," 2018 21st International Conference on Electrical Machines and Systems, 2018, pp. 265-268, doi: 10.23919/ICEMS.2018.8549485.

[5] N. Hashemnia and B. Asaei, "Comparative study of using different electric motors in the electric vehicles," 2008 18th International Conference on Electrical Machines, 2008, pp. 1-5, doi: 10.1109/ICELMACH.2008.4800157.

[6] Y. Sim, N. Niguchi, K. Hirata, and C. Kim, "Coupled analysis of brushless DC motor using finite elements method $\&$ back electromotive force detecting electrical circuits," 2014 International Conference on Electrical Machines (ICEM), 2014, pp. 724-729, doi: 10.1109/ICELMACH.2014.6960261.

[7] P. Magnet and S. Motor, "Chapter 2 Brushless DC Motor," UniMAP, pp. 25-45, 2009.

[8] T. Y. Lee, M. K. Seo, Y. J. Kim, and S. Y. Jung, "Motor Design and Characteristics Comparison of Outer-RotorType BLDC Motor and BLAC Motor Based on Numerical Analysis," in IEEE Transactions on Applied Superconductivity, vol. 26, no. 4, pp. 1-6, June 2016, Art no. 5205506, doi: 10.1109/TASC.2016.2548079.

[9] Y. B. A. Apatya, A. Subiantoro, and F. Yusivar, "Design and prototyping of 3-phase BLDC motor," 2017 15th International Conference on Quality in Research $(Q i R)$ : International Symposium on Electrical and Computer Engineering, 2017, pp. 209-214, doi: 10.1109/QIR.2017.8168483.

[10] S. Ruangsinchaiwanich, Z. Q. Zhu, and D. Howe, "Influence of magnet shape on cogging torque and back-emf waveform in permanent magnet machines," 2005 International Conference on Electrical Machines and Systems, vol. 1, pp. 284-289, 2005, doi: 10.1109/ICEMS.2005.202531.

[11] R. Islam, I. Husain, A. Fardoun, and K. McLaughlin, "Permanent Magnet Synchronous Motor Magnet Designs with Skewing for Torque Ripple and Cogging Torque Reduction," 2007 IEEE Industry Applications Annual Meeting, 2007, pp. 1552-1559, doi: 10.1109/07IAS.2007.240.

[12] I. Kim, N. Nakazawa, S. Kim, C. Park, and C. Yu, "Compensation of torque ripple in high performance BLDC motor drives," Control Engineering Practice, vol. 18, no. 10, pp. 1166-1172, 2010, doi: 10.1016/j.conengprac.2010.06.003.

[13] D. Patterson and R. Spéae, "The design and development of an axial flux permanent magnet brushless DC motor for wheel drive in a solar powered vehicle," in IEEE Transactions on Industry Applications, vol. 31, no. 5, pp. 1054-1061, Sept.-Oct. 1995, doi: 10.1109/28.464519.

[14] S. Xie, X. Wang, C. Qu, X. Wang, and J. Guo, "Impacts of different wind speed simulation methods on conditional reliability indices," Int. Trans. Electr. energy Syst., vol. 20, pp. 1-6, 2013, doi: 10.1002/etep.1851.

[15] P. Pillay and R. Krishnan, "Application characteristics of permanent magnet synchronous and brushless DC motors for servo drives," in IEEE Transactions on Industry Applications, vol. 27, no. 5, pp. 986-996, Sept.-Oct. 1991, doi: 10.1109/28.90357.

[16] Der-Ray Huang, et al., "Cogging torque reduction of a single-phase brushless DC motor," in IEEE Transactions on Magnetics, vol. 34, no. 4, pp. 2075-2077, July 1998, doi: 10.1109/20.706802.

[17] P. Wach and P. Wach, "Brushless DC Motor Drives (BLDC)," Dynamics and Control of Electrical Drives, pp. 281-380, 2011, doi: 10.1007/978-3-642-20222-3_4. 
[18] A. Thakur, "Improvement of Back EMF \& Minimization of Torque Ripple of BLDC Motor," Ijo-Science (International Journal Online of Science), vol. 5, no. 8, pp. 1-7, August 2019, doi: 10.24113/ijoscience.v5i7.220.

[19] S. Edition, "Permanent Magnet Technology," 2002.

[20] T. Miller, "Brushless and Reluctance Motor Drives," Power Engineering Journal, vol. 1, no. 6, pp. 325-331, 1987, doi: 10.1049/pe:19870060.

[21] L. Andaloro, G. Napoli, F. Sergi, S. Micari, G. Agnello, and V. Antonucci, "Development of a new concept electric vehicle for last mile transportations," World Electric Vehicle Journal, vol. 7, no. 3, pp. 342-348, September 2015, doi: 10.3390/wevj7030342.

[22] Y. K. Chin, W. M. Arshad, T. Bäckström, and C. Sadarangani, "Design of a Compact BLDC motor for Transient Applications," European Conference on Power Electronics and Applications, 2001.

[23] R. Delpoux, X. Lin-Shi, and X. Brun, "Torque ripple reductions for non-sinusoidal BEMF Motor: An observation based control approach," IFAC-PapersOnLine, vol. 50, no. 1, pp. 15766-15772, July 2017, doi: 10.1016/j.ifacol.2017.08.2311.

[24] C. Abagnale, et al., "Design and Development of an Innovative E-Bike," Energy Procedia, vol. 101, pp. 774-781, November 2016, doi: 10.1016/j.egypro.2016.11.098.

[25] S. Katoch and R. K. Bindal, "Design and Implementation of Smart Electric Bike Eco-Friendly," IJITEE, vol. 8, no. 6S4, pp. 965-967, 2019, doi: 10.35940/ijitee.F1197.0486S419.

[26] M. Fazil and K. R. Rajagopal, "Development of external rotor single-phase PM BLDC motor based drive for ceiling fan," 2010 Joint International Conference on Power Electronics, Drives and Energy Systems \& 2010 Power India, 2010, pp. 1-4, doi: 10.1109/PEDES.2010.5712573.

\section{BIOGRAPHIES OF AUTHORS}

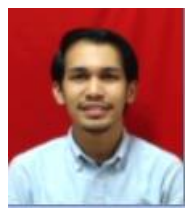

Muhamad `Ariff Khalid was born on 24 October 1995 at Alor Setar, Kedah, Malaysia. In 2020, he received his Bachelor's degree in Electrical Engineering from Universiti Teknikal Malaysia Melaka (UTeM). Currently, he is pursuing her study in Master of Science in Electrical Engineering from the same university. His research study is in machine design.

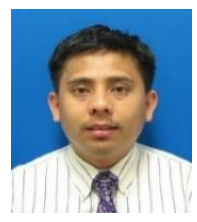

Raja Nor Firdaus Kashfi Raja Othman was born on 02 May 1982 at Parit Buntar, Perak, Malaysia. He received B.Eng., M.Sc. and Ph.D in Electrical Power Engineering from Universiti Putra Malaysia. In 2006, 2009 and 2013, respectively. He is currently senior lecturer in Department of Power Electronics and Drives, Faculty of Electrical Engineering, Universiti Teknikal Malaysia Melaka. His research interest includes applied magnetics, electrical machines, magnetic sensor and drives.

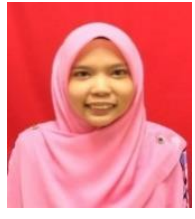

Nor Aishah Md Zuki was born on 9 November 1992 at Kuantan, Pahang, Malaysia. In 2018, she received her Master of Science in Electrical Engineering from Universiti Teknikal Malaysia Melaka (UTeM). Currently, she is pursuing her study in $\mathrm{PhD}$ in Electrical Engineering from the same university. Her research study is in machine design.

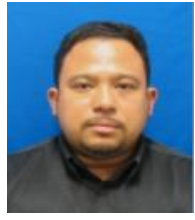

Fairul Azhar Abdul Shukor is a senior lecturer at the Faculty of Electrical Engineering, UniversitiTeknikal Melaka, Malaysia (UTeM), Melaka. He has been with UTeM since 2005. He received his B. Eng. Degree in Electrical and Electronic Engineering and M.Sc. of Electrical Engineering from Universiti Putra Malaysia in 2002 and 2009 respectively. On 2009, he received his Ph.D Eng in Machine Design from Shinshu University, Japan. His areas of interest include electrical machine and actuator design, numerical analysis and machine drive.

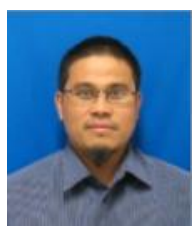

Md Nazri Othman received his Bachelor's degree in Electrical Engineering from Memphis State University, USA in 1989. He then obtained his Master of Science degree in Power Electronic and Drives from University of Nottingham, UK in 2005. He received his Ph.D degree from University of Nottingham in 2011. He has served as an academic staff at Universiti Teknikal Malaysia Melaka (UTeM) since 2003 and he is currently an associate professor in Faculty of Electrical Engineering, UTeM. His research interests include electric machines design, renewable energy and power system design.

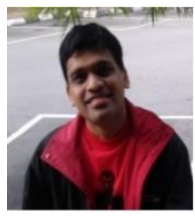

Chockalingam Aravind Vaithilingam received his Bachelor's degree in Electrical \& Electronic Engineering from Bharathiyar University, India. He then obtained his Master of Science degree in Power Electronic and Drives from same university. He received his Ph.D degree from Universiti Putra Malaysia (UPM), Malaysia. He has served as an academic staff at Taylor's University since 2017 and he is currently an associate professor in Electrical and electronic Engineering, Faculty of Innovation and Technology, Taylor's University. 